REVIEW

\title{
Early management of adults with an uncomplicated first generalised seizure
}

M J G Dunn, D P Breen, R J Davenport, A J Gray

Emerg Med J 2005;22:237-242. doi: 10.1136/emj.2004.015651

A literature review of first seizures in adults was performed and a management algorithm was constructed. This review highlights the importance of a thorough history and examination, routine biochemistry and haematology, an electrocardiogram, selected neuroimaging, discharge planning with driving and lifestyle advice, and follow-up in a specialist clinic.

See end of article for authors' affiliations

....

Correspondence to: Mr M J G Dunn, Emergency Department The Royal Infirmary of Edinburgh at Little France, 51 Little France Crescent, Old Dalkeith Road, Edinburgh, EH16 4SA, Scotland; dr@smithsondunn. demon.co.uk

Received 28 February 2004 Revised version received 28 February 2004 Accepted for publication 1 April 2004
$\mathrm{S}$ eizures are a frequent reason for attendance been reported that $0.24-0.3 \%$ of adults who present to the ED do so because of a first seizure. $^{12}$ Around 5\% of the population will experience at least one non-febrile seizure during their lifetime. ${ }^{3}$ Various studies have looked at the investigation and management of first adult seizures but often no consensus has been reached. It has been proposed that treatment and referral guidelines should be agreed between ED staff and neurologists. ${ }^{5}$ This review assesses the literature and formulates a clinical pathway (fig 1) for adults who present with a suspected first-ever generalised seizure and fully recover with no neurological deficit. Such a pathway is needed because unlike epilepsy, where Managed Clinical Networks and the Government Action Plan on Epilepsy Services are set to improve the standard of care in the UK, ${ }^{6}{ }^{7}$ many emergency physicians differ in their approach to first seizures. ${ }^{5}$ This pathway should reduce variable low-up, and avoid unnecessary admissions. Seizures may be provoked by a variety of factors including toxins (most commonly alcohol), metabolic disturbances, head trauma, and sleep deprivation. It is artificial to discriminate between non-traumatic seizure types during initial management. This pathway does not include patients with known epilepsy, seizures related to head trauma, or seizures related to eclampsia. The emergency management of an actively seizing patient is not addressed.

\section{SEARCH STRATEGY}

The key clinical question was how to manage an adult who presents to the ED following an uncomplicated first generalised seizure. Several electronic databases (Medline, CINAHL, EMBASE, and Cochrane library) were searched using the following strategy: [seizure\$.ti. OR epilep\$.ti.] AND [first\$.ti. OR new\$.ti. OR isolated.ti. OR unprovoked.ti. OR emergency.ti.] NOT [child\$.ti. OR status epilepticus.ti.] LIMIT to the emergency department (ED). It has management, streamline investigations and fol- to human AND English. The references generated were sifted for relevance based on their title and abstract, and other references were followed-up from the papers identified. The internet was searched using the Google search engine.

\section{DIFFERENTIAL DIAGNOSIS OF SEIZURES}

Several conditions can mimic a seizure. A clear history from the patient, and an eyewitness if possible, is crucial in determining whether or not the episode was epileptiform. Prodromal symptoms occurring prior to the episode, such as déjà $\mathrm{vu}$, stereotyped tastes or smells, or rising abdominal sensation, may point to a diagnosis of first seizure. These may however, be confused with presyncopal symptoms such as light-headedness and visual disturbance. ${ }^{8}$ Tongue biting is suggestive of a seizure, ${ }^{89}$ unlike incontinence, which is not specific and can occur in any type of collapse where the patient has a full bladder.' History of head trauma, history of stroke, and family history of epilepsy are all independent risk factors for first seizure. ${ }^{10}$ In some cases, it may be possible to identify a provoking factor for the seizure such as excessive alcohol intake, alcohol withdrawal, drug misuse, sleep deprivation, or flashing lights.

Syncope, whatever the aetiology, is often a source of confusion, particularly when there is jerking or other movements normally associated with seizures. In Lempert's study of 56 medical students with self-induced syncope, myoclonic jerking occurred in $90 \%$ of subjects. ${ }^{11}$ However, recovery of awareness in syncope is rapid, commonly within 10 seconds, whereas patients often recover over minutes through confusion and drowsiness following a seizure. ${ }^{12}$ Pallor is typically seen in patients with syncope but its use in discriminating between epileptic and nonepileptic attacks has been questioned. ${ }^{8}$

The diagnosis of non-epileptic attacks, also known as pseudo-seizures or hysterical seizures, is difficult. They should only be confidently diagnosed by an epilepsy specialist. Staff may recognise attacks as atypical, ${ }^{12}$ but this is often unreliable and even experts are fooled. It may be helpful to carefully review the patient's

Abbreviations: ACEP, American College of Emergency Physicians; CT, computer tomography; DDA, Disability Discrimination Act; DVLA, Driving and Vehicle Licensing Agency; ED, emergency department; ECG, electrocardiogram; EEG, electroencephalogram; FIRST Group, First Seizure Trial Group; GGT, gamma-glutamyl transpeptidase; MCV, mean cell volume; MESS, Medical Research Council Multicentre Study of Early Epliepsy and Single Seizure; MRI, magnetic resonance imaging; SIGN, Scottish Intercollegiate Guidelines Network 


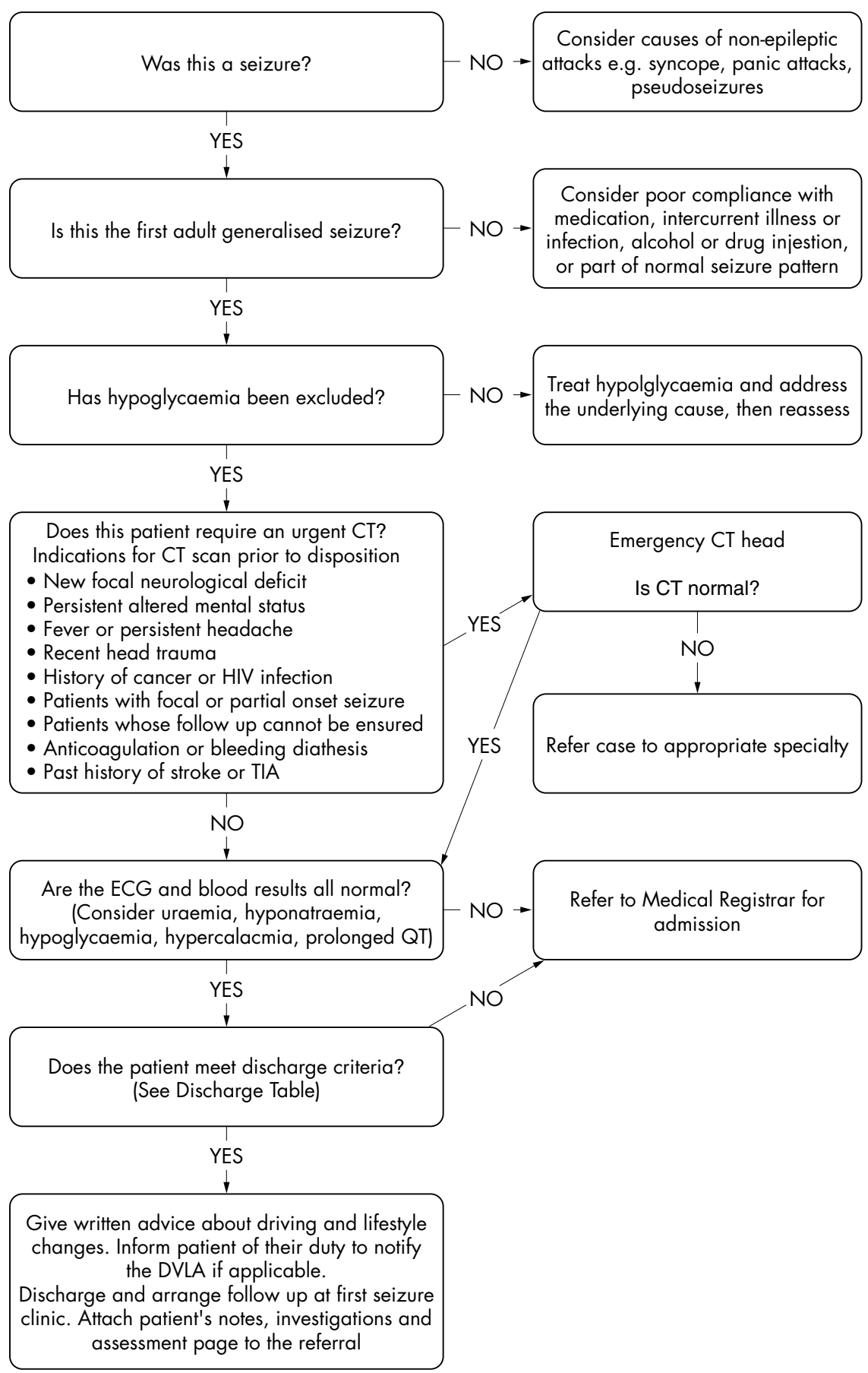

Figure 1 Algorithm for the management of adults with an uncomplicated first generalised seizure. psychiatric history in cases where non-epileptic attacks are suspected. However, it is easy to make mistakes when dealing with non-epileptic attacks and the ED is probably not the place to diagnose them. The safest policy is to assume that seizures are real until proven otherwise, or until the patient has been referred to a first seizure clinic.

Other conditions which can be misdiagnosed as epileptic attacks include hypoglycaemia, cardiac arrhythmias, carotid sinus hypersensitivity, panic attacks, and hyperventilation. ${ }^{12}$ Patients presenting with these conditions should be investigated and treated differently in the ED, and may need referral to an appropriate clinic such as cardiology or psychiatry. It may be necessary for more than one specialty to become involved in the patient's care.
The ED is the best place to obtain an accurate contemporaneous history, including a witness account. The best way to discriminate between seizures and other mimics is from the history.

\section{INVESTIGATIONS}

\section{Blood tests}

Various metabolic disturbances, including hypoglycaemia, hyponatraemia, and uraemia, can provoke seizures..$^{13}$ Studies have found that $2.4-8 \%$ of patients have metabolic abnormalities associated with their first generalised seizure, but often these are clinically insignificant. ${ }^{13-18}$ There is debate as to whether blood tests are of any value initially, with different studies offering different opinions. ${ }^{12} 13171920$ Many of these 
studies involve small numbers and are subject to Type II error. Retrospective studies have suggested that various blood tests can distinguish the need for admission, but by design such studies are biased and do not address long-term benefit. ${ }^{16} 17$

The current evidence suggests that routine blood testing will only reveal a small proportion of patients with significant metabolic abnormalities. However, these few abnormalities may influence management and the need for admission. We suggest that testing for glucose, serum electrolytes, calcium and full blood count is essential in the ED setting, in combination with additional blood tests only if they are clinically indicated.

\section{Neuroimaging}

Studies have quoted that up to $41 \%$ of adults have an abnormal computer tomography (CT) scan following their first generalised seizure. ${ }^{17-23}$ Having said this, only 6-10\% are abnormal if there are no focal neurological signs on examination. $^{22} 23$ The American College of Emergency Physicians (ACEP) include neuroimaging as part of their evaluation of first seizures. ${ }^{20}$ The Scottish Intercollegiate Guidelines Network (SIGN) guidelines recommend brain imaging in all cases where a confident diagnosis of an idiopathic generalised epilepsy syndrome cannot be made. ${ }^{8}$ There is a consensus that yield from scanning increases with age, and this has led to some physicians operating an agedependent policy with regard to neuroimaging. ${ }^{19}$ Lesions such as cortical atrophy and cerebral infarction account for most of the abnormal scans. ${ }^{22}$ Many studies have suggested that neuroimaging is helpful in making or excluding specific diagnoses, quantifying risk of seizure recurrence and guiding management. ${ }^{14-16}{ }^{22-26}$ However, if the patient recovers fully from their seizure, this may be performed as an out-patient procedure. Anyone, regardless of age, who has suffered a partial-onset seizure, or who has persisting focal neurological signs, requires neuroimaging.

The type of imaging has also been addressed. The SIGN guidelines recommend magnetic resonance imaging (MRI) over CT where resources permit. ${ }^{8}$ Studies have found that MRI detects lesions that CT does not, such as mesial temporal sclerosis, cortical dysplasia, vascular malformations, and some tumours. ${ }^{812} 27$ Interestingly, it has been reported that patients are likely to have a better outcome if their intracranial tumour presents with a seizure rather than other progressive signs such as headache. ${ }^{28}$ Tumours that are not obvious on CT scan are likely to be low grade gliomas. ${ }^{29}$

There is a lack of consensus in the literature as to whether neuroimaging should form part of the initial management of an adult who has suffered a first seizure episode from which they have fully recovered. There appears to be a transatlantic divide, with US studies supporting the liberal use of neuroimaging and SIGN guidelines recommending neuroimaging only in selected patient groups. The decision that has to be made in the ED is whether the patient needs an emergency scan or whether this can wait to be performed as an out-patient if required. The indications for emergency neuroimaging are outlined in the algorithm below. Initial neuroimaging is likely to be a CT scan as this is now widely available.

\section{Electroencephalogram (EEG)}

The SIGN guidelines recommend an EEG in all young patients presenting with a generalised seizure. An EEG may also be helpful in supporting the diagnosis in older patients, but the EEG should not be used to exclude the diagnosis of epilepsy. ${ }^{8}$ Many studies have found EEG to be useful in defining seizure type, quantifying risk of recurrence, and quantifying likelihood of finding diagnostic abnormalities. ${ }^{16} 19262730$ However, EEG has a $0.5-4 \%$ false positive rate and a relatively low sensitivity. ${ }^{81}$ Also, the positive predictive value of routine interictal EEG in a young healthy adult population is $2-3 \%$, and even higher in the elderly. ${ }^{31}$ The decision as to whether an EEG is indicated is best left to a specialist. As EEGs may be recorded at specialist units with long waiting lists, the impact on initial management is likely to be minimal. ${ }^{14} 1619$

An EEG is an unnecessary investigation in the ED, and the decision as to whether it might be helpful should be made in a first seizure clinic.

\section{Other tests}

ACEP states that alcoholics can have a seizure as a result of excessive alcohol intake, abstinence, complications of their alcoholism, or an underlying seizure disorder. ${ }^{20}$ Alcohol intake $>50 \mathrm{~g} /$ day (equivalent to $>44 \mathrm{UK}$ units/week) was found to be an independent risk factor associated with first generalised tonic-clonic seizures in a recent study. ${ }^{10}$ Indeed, alcohol has been implicated as a precipitating factor in up to one third of seizures. ${ }^{14} 15192532$ It would seem prudent to measure breath alcohol level in the ED as this may give a clue as to aetiology. Measurement of gamma-glutamyl transpeptidase (GGT) and mean cell volume (MCV) may indicate chronic alcohol consumption.

An electrocardiogram (ECG) should be routinely performed as this is a cheap and non-invasive test which can detect other causes of collapse such as cardiac ischaemia and Wolff-Parkinson-White syndrome. Long-QT syndrome, which can present as a seizure, may also be detected. ${ }^{33}$ Routine skull X-rays and chest X-rays are not appropriate unless there is a specific indication e.g. head trauma or specific chest pathology.

Measurement of breath alcohol and an ECG should be routinely performed in the ED. Liver function tests and plain radiographs should only be ordered if there is a specific indication.

\section{TREATMENTS}

\section{Anticonvulsant medication}

The SIGN guidelines suggest that it is reasonable to recommend prophylactic anticonvulsant treatment only if the patient has had previous myoclonic, absence, or partial seizures; if an EEG shows unequivocal epileptic discharges; if the patient has a congenital neurological deficit; or if the patient or physician considers the risk of recurrence to be unacceptable. ${ }^{8}$ The risk of recurrence following a first unprovoked seizure varies substantially depending on seizure type, imaging, and EEG findings. Overall, the risk of recurrence is between $30-40 \%{ }^{34}$ this is greatest in the first six months and falls to $<10 \%$ after 2 years. ${ }^{26}$ The First Seizure Trial (FIRST) Group concluded that the probability of longterm remission was not influenced by treatment of the first seizure. $^{35}$ Many studies have agreed that anticonvulsant therapy should be withheld until a clearer epileptic pattern is established although neuroimaging, EEG, occupation, or patient opinion may influence this decision. ${ }^{14171936}$ The Medical Research Council Multicentre Study of Early Epilepsy and Single Seizure (MESS) is also currently addressing this important issue. Seizures provoked only by alcohol withdrawal, metabolic or drug-related causes, or sleep deprivation should not be treated with antiepileptic drugs. Patients should not be treated if there is uncertainty about the diagnosis. ${ }^{8}{ }^{31}$

Evidence indicates that anticonvulsant medication should only be prescribed to patients following their first generalised seizure when the risk of seizure recurrence is particularly high. It is our opinion that prophylactic antiepileptic drugs should not routinely be prescribed in the ED, but only after 
consultation with a neurologist or other specialist with an interest in epilepsy.

\section{Driving and lifestyle advice}

The Driver and Vehicle Licensing Agency (DVLA) states that following a first epileptic seizure/solitary fit, drivers who have group 1 entitlement (motor cars and motorcycles) should refrain from driving for one year with subsequent medical review before restarting driving. ${ }^{37}$ If they continue to drive, their motor insurance will not be valid. A doctor has a duty to advise patients of these facts and of the patient's duty to inform the DVLA. Doctors should keep a written record of the fact that this counselling has taken place. ${ }^{38}$ Audits of clinical records reveal that in only $0.9-21 \%$ of cases was it documented that such advice had been given. ${ }^{19} 192$ However, this may be artificially low as some patients may be non-drivers and others may have been given verbal advice without documentation.

Practitioners are probably also poor at informing patients about changes in lifestyle/occupation that would be prudent to make following an unprovoked seizure. Having had a single seizure should not materially affect most people's

Management of adults with an uncomplicated first generalised seizure

\begin{tabular}{|l|l|l|}
\hline Inclusion Criteria & $\begin{array}{l}\text { Patients > 16 yrs; Clear history of first generalised } \\
\text { seizure; Seizures related to drug or alcohol } \\
\text { ingestion or withdrawal }\end{array}$ & $\begin{array}{l}\text { Name } \\
\text { DoB } \\
\text { Address }\end{array}$ \\
\hline Exclusion Criteria & $\begin{array}{l}\text { Patients with non-epileptic attacks (e.g. syncope, } \\
\text { panic attacks, pseudoseizures); Patients with } \\
\text { known seizure or metabolic disorder; Seizures } \\
\text { related to recent trauma or eclampsia }\end{array}$ \\
\hline
\end{tabular}

History Table

\begin{tabular}{|l|l|}
\hline & \\
\hline Witness history & \\
\hline Type of seizure (generalised, partial) & \\
\hline $\begin{array}{l}\text { Previous history of seizures, febrile fits, birth trauma, } \\
\text { meningitis, head injuries }\end{array}$ & \\
\hline Family history of seizures & \\
\hline Possible precipitating events (alcohol, drugs, sleep deprivation) & \\
\hline
\end{tabular}

Observations Table

\begin{tabular}{|c|c|c|c|c|c|c|c|c|c|c|}
\hline \multicolumn{3}{|c|}{ Temperatur } & & \multicolumn{2}{|l|}{ Pulse } & \multicolumn{2}{|l|}{ BP } & BM & \multicolumn{2}{|c|}{ Breath Alcohol } \\
\hline \multicolumn{3}{|c|}{ GCS } & & \multicolumn{3}{|c|}{ Pupils } & \multicolumn{4}{|c|}{ Limb movement } \\
\hline & & & \multicolumn{2}{|c|}{ Right } & \multicolumn{2}{|c|}{ Left } & \multirow[t]{3}{*}{ R. arm } & \multirow[t]{3}{*}{ L. arm } & \multirow[t]{3}{*}{ R. leg } & \multirow[t]{3}{*}{ L. leg } \\
\hline $\mathrm{E}$ & M & $\mathrm{v}$ & Size & Reaction & Size & \begin{tabular}{|l|} 
Reaction \\
\end{tabular} & & & & \\
\hline & & & & & & & & & & \\
\hline
\end{tabular}

Investigation Table (Enter results)

\begin{tabular}{|c|c|c|}
\hline \multicolumn{3}{|c|}{ 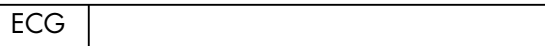 } \\
\hline Urea & $\mathrm{HB}$ & \\
\hline Creat & $\overline{M C V}$ & \\
\hline $\mathrm{Na}$ & WCC & \\
\hline $\mathrm{K}$ & PLT & \\
\hline $\mathrm{CO} 2$ & Bil & \\
\hline $\mathrm{Ca}$ & GGT & \\
\hline Alb & ALT & \\
\hline Glu & Alk Ph & \\
\hline CT & & \\
\hline
\end{tabular}

Indications for CT scan prior to disposition

- New focal neurological deficits

- Persistent altered mental status

- Fever or persistent headache

- Recent head trauma

- History of cancer or HIV infection

- Patients with focal or partial onset seizure

- Patients whose follow up cannot be ensured

- Anticoagulation or bleeding diathesis

- Past history of stroke or TIA

Discharge Table

\begin{tabular}{|l|l|}
\hline Patient has fully recovered with no persistent neurological symptoms or signs (incl. headache) & \\
\hline Normal observations and investigations (incl. temperature) & \\
\hline $\begin{array}{l}\text { Patient has been given written advice about driving and lifestyle changes, and has been } \\
\text { informed of their duty to notify the DVLA, if appropriate }\end{array}$ & \\
\hline Patient has a responsible adult to stay with following discharge & \\
\hline Patient will attend follow up & \\
\hline First seizure clinic follow up arranged. Copies of all notes and investigations forwarded & \\
\hline
\end{tabular}

Figure 2 Data chart for the management of adults with an uncomplicated first generalised seizure. 
employment. If the job involves driving, working at heights or working with machinery, there may be some restrictions. Patients should be advised to tell their employer that they have had a seizure in order to fulfil the requirements of Health and Safety at Work legislation. ${ }^{39}$ However, they are protected by the Disability Discrimination Act (DDA) and their employer is expected to make reasonable adjustments in order to allow them to continue working. ${ }^{40}$ The DDA applies to employers with 15 or more employees.

It is important to emphasise to patients that having a seizure should not stop them from doing the things they enjoy, although sensible safety precautions do need to be taken. For example, when swimming, patients should be accompanied by someone who is capable of managing a seizure. Lindsten recently reported that adults with a newlydiagnosed unprovoked epileptic seizure become significantly less physically active, travel abroad less often, and are generally less active during their leisure time than sex- and age-matched referents. ${ }^{41}$

Patients should be given verbal and written advice about driving and lifestyle changes prior to being discharged from the ED. In Lothian, a first seizure information leaflet has been produced for this purpose. ${ }^{42}$

\section{DISPOSITION \\ Discharge}

US retrospective studies have used various criteria to determine the need for admission in adults presenting with a first seizure, often including a battery of tests. ${ }^{16}{ }^{17}$ Test result abnormalities were often predictable from history and examination clues and ultimately only half of patients with new-onset seizures unrelated to trauma, hypoglycaemia, alcohol, or drug use required admission. One study advised admission for all patients quoting a high early seizure recurrence rate. ${ }^{15}$ However, this is unlikely to apply to unprovoked seizures without neurologic deficit if a subgroup analysis is applied. Many studies have agreed admission is probably only necessary if the patient remains drowsy or comatose; if a neurological examination reveals abnormalities suggestive of an underlying structural or treatable cause e.g. meningoencephalitis; if the patient is at high risk of further seizures e.g. alcohol withdrawal; or if the patient cannot be supervised by a responsible adult. ${ }^{12} 143$ Despite this, first seizure patients in the UK are often referred to the inpatient medical team, ${ }^{14}$ which is unnecessary and undesirable.

Following a first generalised seizure, adults who have fully recovered, have no neurological deficit, have normal initial investigations, have a responsible adult to stay with, and who are likely to attend out-patient investigations and follow-up can be discharged from the ED.

\section{Follow-up}

The SIGN guidelines state that all patients with a suspected first-ever generalised seizure should be followed-up in a dedicated first seizure clinic. ${ }^{8}$ Davidson suggested that management of patients with definite or probable seizures depends upon the resources available but should ideally be provided by a physician with an interest in epilepsy. ${ }^{44}$ This suggestion is supported by the SIGN guidelines which define an epilepsy specialist as "a consultant with expertise in epilepsy as demonstrated by training and continuing education in epilepsy, peer review of practice and regular audit of diagnosis". ${ }^{8}$ A consensus statement from the Royal College of Physicians of Edinburgh proposes that epilepsy must be a significant part of these consultants' clinical workload, equivalent to at least one session per week. ${ }^{45}$

Follow-up for adults with a suspected first-ever generalised seizure should consist of consultation with an epilepsy specialist in a first seizure clinic, ideally within six weeks of presentation. Epilepsy specialist nurses are also now in place in certain parts of the country to provide support to patients.

\section{CONCLUSIONS}

Although many studies have looked at various elements of management of a first generalised seizure in adults, there still seems to be a lack of consensus. A clinical pathway should not only streamline management but also avoid unnecessary investigations and admissions. This pathway is adapted to allow for local opinion as well as local resources but would apply well for many areas of the UK and other parts of the world. We would recommend that an adult with a first generalised seizure can be managed in the ED using the algorithm (fig 1) and data chart (fig 2) presented in this paper. We are currently reviewing the management and follow-up of adults who have presented to The Royal Infirmary of Edinburgh and have been managed according to this algorithm.

\section{ACKNOWLEDGEMENTS}

The authors would like to thank Fiona McKinnon (epilepsy specialist nurse) for producing the first seizure information leaflet.

\section{CONTRIBUTORS}

Alasdair Gray had the original idea for the review. Mark Dunn performed the literature review, appraised the articles found, wrote the paper, constructed the algorithm, and will act as guarantor for the paper. David Breen updated the review and wrote the paper. Richard Davenport and Alasdair Gray edited the paper.

\section{Authors' affiliations}

M J G Dunn, Emergency Department, The Royal Infirmary of Edinburgh at Little France, Edinburgh, Scotland

D P Breen, College of Medicine and Veterinary Medicine, University of Edinburgh, Edinburgh, Scotland

R J Davenport, Department of Clinical Neurosciences, Western General Hospital, Edinburgh, Scotland

A J Gray, Emergency Department, The Royal Infirmary of Edinburgh at Little France, Edinburgh, Scotland

The Department of Clinical Neurosciences received a grant from GlaxoSmithKline to fund the first seizure clinic in its first year.

Competing interests: none declared

\section{REFERENCES}

1 Krumholz A, Grufferman S, Orr ST, et al. Seizure and seizure care in an emergency department. Epilepsia 1989;30:175-81.

2 Huff JS, Morris DL, Kothan RU, et al. Emergency department management of patients with seizures: a multicenter study. Acad Emerg Med 2001;8:622-8.

3 Forsgren L, Bucht G, Eriksson S, et al. Incidence and clinical characterization of unprovoked seizures in adults: a prospective population-based study. Epilepsia 1996;37:224-29.

4 Hauser WA, Annegers JF, Kurland LT. Incidence of epilepsy and unprovoked seizures in Rochester, Minnesota; 1935-1984. Epilepsia 1993;34:453-68.

5 Reuber M, Hattingh L, Goulding PJ. Epileptological emergencies in accident and emergency: a survey of St James's university hospital, Leeds. Seizure 2000;9:216-20.

6 Scottish Executive Health Department. Promoting the development of Managed Clinical Networks in NHS Scotland. NHS Circular: HDL (2002)69, September 18, 2002.

7 Department of Health. Government Action Plan on Epilepsy Services in England. 2003. Available at URL, http://www.doh.gov.uk/cmo/epilepsy/ epilepsyactionplan.pdf, (accessed 12 January 2004)).

8 Scottish Intercollegiate Guidelines Network. Diagnosis and management of epilepsy in adults. April, 2003.

9 Manford M. Assessment and investigation of possible epileptic seizures. Journal of Neurology, Neurosurgery \& Psychiatry 2001;70(suppl 2):3-8.

10 Leone $M$, Bottachi $E$, Beghi $E$, et al. Risk factors for a first generalised tonicclonic seizure in adult life. Neurological Sciences 2002;23:99-106.

11 Lempert T, Baver M, Schmidt D. Syncope: a videometric analysis of 56 episodes of transient cerebral hypoxia. Ann Neurol 1994;36:233-7.

12 Wills AJ, Stevens DL. Epilepsy in the accident and emergency department. Br J Hosp Med 1994;52:42-5.

13 Turnbull TL, Vanden Hoek TL, Howes DS, et al. Utility of laboratory studies in the emergency department patient with a new-onset seizure. Ann Emerg Med $1990 ; 19: 373-7$. 
14 Morrison AD, McAlpine $\mathrm{CH}$. The management of first seizures in adults in a district general hospital. Scot Med J 1997;42:73-5.

15 Tardy B, Lafond $\mathrm{P}$, Convers $\mathrm{P}$, et al. Adult first generalized seizure: etiology, biological tests, EEG, CT scan, in an, eds. Am J Emerg Med 1995;13:1-5.

16 Rosenthal RH, Heim ML, Waeckerle JF. First time major motor seizures in an emergency department. Ann Emerg Med 1980;9:242-5.

17 Henneman PL, DeRoos F, Lewis RJ. Determining the need for admission in patients with new-onset seizures. Ann Emerg Med 1994;24:1108-14.

18 Powers RD. Serum chemistry abnormalities in adult patients with seizures. Ann Emerg Med 1985;14:416-20.

19 Edmondstone WM. How do we manage the first seizure in adults? J R Coll Physicians Lond 1995;29:289-94.

20 American College of Emergency Physicians. Clinical policy for the initial approach to patients presenting with a chief complaint of seizure who are not in status epilepticus. Ann Emerg Med 1997:29:706-24.

21 Sempere AP, Villaverde FJ, Martinez-Menendez B, et al. First seizure in adults: a prospective study from the emergency department. Acta Neurol Scand 1992;86:134-8.

22 Ramirez-Lasepas M, Cipolle RJ, Morillo LR, et al. Value of computed tomographic scan in the evaluation of adult patients after their first seizure. Ann Neurol 1984; 15:536-43.

23 Young AC, Constanzi JB, Mohr PD, et al. Is routine computed axial tomography in epilepsy worthwhile? Lancet 1982;ii:1446-7.

24 Greenberg MK, Barsan WG, Starkman S. Neuroimaging in the emergency patient presenting with seizure. Neurology 1996;47:26-32.

25 Schoenenberger RA, Heim SM. Indication for computed tomography of the brain in patients with first uncomplicated generalised seizure. BMJ 1994:309:986-9.

26 Hopkins A, Garman A, Clarke C. The first seizure in adult life. Value of clinical features, electroencephalograph, and computerised tomographic scanning in prediction of seizure recurrence. Lancet 1988;1:721-6.

27 King MA, Newton MR, Jackson GD, et al. Epileptology of the first seizure presentation: a clinical electroencephalographic and magnetic resonance imaging study of consecutive patients. Lancet 1998;352:1007-1 1 .

28 Smith DF, Hutton JL, Sandemann D, et al. The prognosis of primary intracerebral tumours presenting with epilepsy: the outcome of medical and surgical management. Journal of Neurology, Neurosurgery \& Psychiatry 1991;54:915-20.

29 Chadwick D, Smith D. Epileptology of the first-seizure presentation [letter]. BMJ 1998;352:1855.
30 Van Donselaar CA, Geerts AT, Schimsheimer RJ. Idiopathic first seizure in adult life: who should be treated. BMJ 1991;302:620-3.

31 Ministry of Health. Diagnosis and management of epilepsy in adults. Ministry of Health Clinical Practice Guidelines. 1999.

32 Ryan J, Nash S, Lyndon J. Epilepsy in the accident and emergency department - developing a code of safe practice for adult patients. South East and South West Thames Accident and Emergency Specialty Sub-committees. J Accid Emerg Med 1998;15:237-43.

33 Pacia SV, Devinsky O, Luciano DJ, et al. The prolonged QT syndrome presenting as epilepsy: a report of two cases and literature review. Neurology 1994;44:1408-10.

34 Berg AT, Shinnar S. The risk of seizure recurrence following a first unprovoked seizure. Neurology 1991:41:965-72.

35 Musicco M, Beghi E, Solari A, et al. Treatment of first tonic-clonic seizure does not improve the prognosis of epilepsy. Neurology 1997;49:991-8.

36 Willmore $\mathrm{L}$. Epilepsy emergencies: the first seizure and status epilepticus. Neurology 1998:51(suppl 4):534-8.

37 Driving and Vehicle Licensing Agency. DVLA - At a glance. Chapter 1. Neurological Disorders. Available at URL, http://www.dvla.gov.uk/ at_a_glance/chl_neurological.html, (accessed 12 January 2004).

38 Taylor JF, ed. Medical aspects of fitness to drive. $5^{\text {th }}$ ed. London: Medical Commission on Accident Prevention, 1995.

39 The Management of Health and Safety at Work Regulations 1999. HMSO. 1999. Available at URL, http://www.hmso.gov.uk/si/si1999/ 19993242.html, (accessed 12 January 2004)).

40 Disability Discrimination Act 1995 (c.50). HMSO. 1999. Available at URL, http://www.hmso.gov.uk/acts1995/1995050.html, (accessed 12 January 2004).

41 Lindsten $\mathrm{H}$, Stenlunel H, Forsgren L. Leisure time and social activity after a newly diagnosed epileptic seizure in adult age. A population-based casereferent study. Acta Neurol Scand 2003;107:125-33.

42 NHS Lothian. First seizure information leaflet. November, 2003.

43 Pellegrino TR. An emergency department approach to first-time seizures. Emerg Med Clin North Am 1994;12:925-39.

44 Davidson DL. What to do with first fits. Scot Med J 1999;44:6-8.

45 Royal College of Physicians of Edinburgh. Consensus conference on better care for children and adults with epilepsy. Final consensus statement. 2002. Available at URL, http://www.rcpe.ac.uk/esd/consensus/ better_care_02.html, (accessed 12 January 2004).

\section{Call for papers}

\section{Ambex 2005 International Conference and Exhibition}

The $7^{\text {th }}$ meeting of the 999 EMS research forum is taking place on 30 June to 2 July 2005 in Harrogate.

Research can cover any aspect of 999 prehospital emergency healthcare. Selected abstracts will be published in the Emergency Medicine Journal.

The abstract submission deadline is Monday 9 May.

For further information and an abstract submission form contact Anne Surman (email: a.g.surman@swansea.ac.uk) 